\title{
Cracking Driving Force at the Tip of SCC under Heterogeneous Material Mechanics Model of Safe-End Dissimilar Metal-Welded Joints in PWR
}

\author{
Yuman Sun $\mathbb{D}^{1},{ }^{1}$ He Xue $\mathbb{D}^{1},{ }^{1}$ Kuan Zhao ${ }^{\mathbb{D}},{ }^{1}$ Yubiao Zhang, ${ }^{1}$ Youjun Zhao, ${ }^{1}$ \\ Weiming Yan, ${ }^{1}$ and Rehmat Bashir $\mathbb{D}^{1,2}$ \\ ${ }^{1}$ School of Mechanical Engineering, Xi'an University of Science \& Technology, Xi'an 710054, China \\ ${ }^{2}$ Department of Mechanical Engineering, University of Engineering and Technology, Lahore 54890, Pakistan \\ Correspondence should be addressed to Yuman Sun; 19205201061@stu.xust.edu.cn and He Xue; xuehe@xust.edu.cn
}

Received 21 September 2021; Accepted 29 December 2021; Published 13 January 2022

Academic Editor: Klaudio Bari

Copyright (c) 2022 Yuman Sun et al. This is an open access article distributed under the Creative Commons Attribution License, which permits unrestricted use, distribution, and reproduction in any medium, provided the original work is properly cited.

\begin{abstract}
The complicated driving force at the stress corrosion cracking (SCC) tip of the safe-end dissimilar metal-welded joints (DMWJs) in the pressurized water reactor (PWR) is mainly caused by the heterogeneous material mechanical properties. In this research, to accurately evaluate the crack driving force at the SCC in DMWJs, the stress-strain condition, stress triaxiality, and $J$-integral of the crack tip at different positions are analyzed based on the heterogeneous material properties model. The results indicate that the larger driving force will be provided for the I-type crack when the crack is in the SA508 zone and the interface between the 316L region and base metal. In addition, the heterogeneous material properties inhibit the $J$-integral of the crack in the 316L region, which has a promoting effect when the crack is in the SA508 zone and weld metal. It provides a new idea for analyzing driving force at the crack tip and safety evaluation of DMWJs in PWRs.
\end{abstract}

\section{Introduction}

The welded structure of the primary circuit of the pressurized water reactors (PWR) works under irradiations, high temperature, high pressure, and corrosion environments. The austenitic stainless steel and nickel-based alloy with excellent high-temperature mechanical properties and corrosion resistance have been widely used for structural welding materials in nuclear power plant's (NPP) primary circuits [1-4]. Previous research and practices have shown that corrosion resistance is mainly due to the formation of chromium-rich oxide film on the metal surface. However, the environment-assisted cracking (EAC) is represented by stress corrosion cracking (SCC) in high-temperature and high-pressure water environments produced by the local oxide film rupture with mechanical and material synergy [5-8]. The schematic diagram of the SCC in the welded joint at the safe-end of the primary circuit of the PWR is displayed in Figure 1.
Accurate measurement of the mechanical properties of the welded joint in the safe-end of the in-service nuclear power equipment is an effective means to ensure its safe operation. Several studies have demonstrated that the microstructure and mechanical properties in the heat-affected zone (HAZ) and fusion zone (FZ) of the DMWJ are complicatedly distributed [9-13]. On this basis, the heterogeneous mechanical properties of the DMWJs in PWRs will cause the complexity of the driving force at the crack tip. Several studies have attempted to evaluate the local material mechanical proprieties of the safe-end DMWJ. Some scholars $[14,15]$ have obtained the mechanical proprieties of the Alloy52M DMWJ in the PWR by the microhardness test or minisized tensile test. The experiment illustrates the acute change in the strength (yield strength and tensile strength) at the interface between the materials. At the same time, some researchers have proposed that the driving force at the crack tip of welded structures can be analyzed by the stress triaxiality and plastic strain condition around the crack tip 


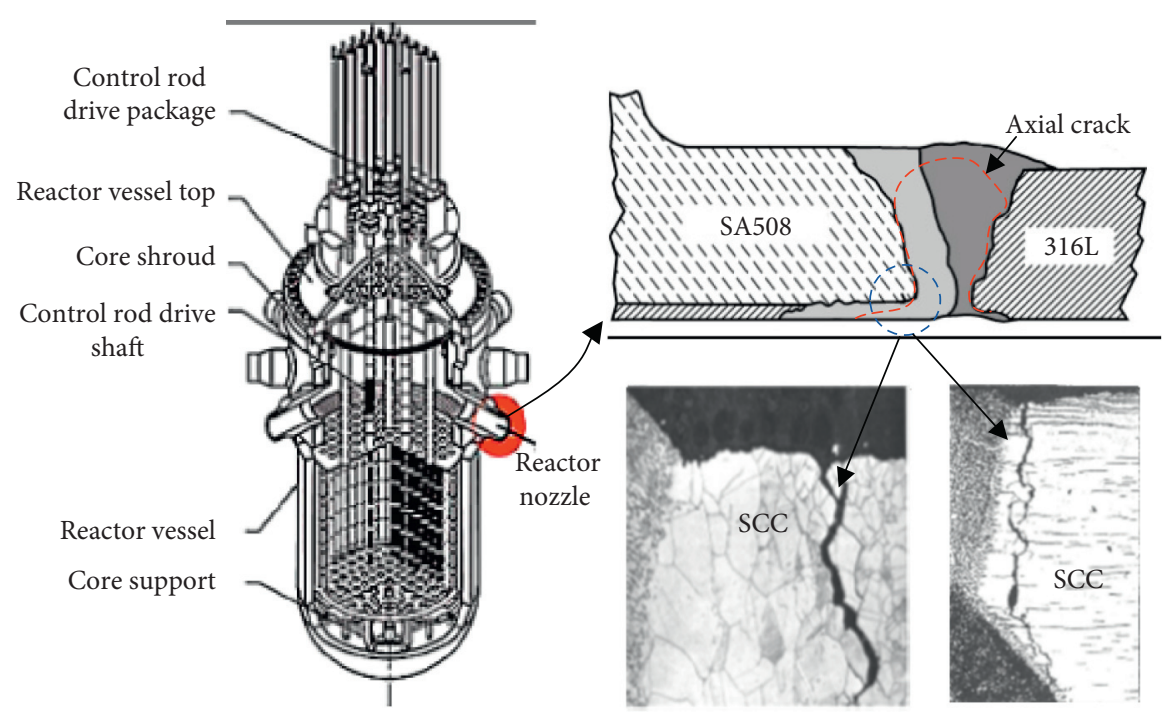

FIGURE 1: Schematic diagram of the stress corrosion cracking in the welded joint at the safe-end of the primary circuit of the PWR.

$[16,17]$. Peng et al. $[18,19]$ have studied the effect of strength mismatch on the SCC driving force of DMWJs and found that the heterogeneous material properties have a retardation effect on the driving force of SCC initiation between the dilution zone and base metal. Lingyan et al. [11] studied the effect of the heterogeneous material mechanical properties on the crack driving force of DMWJs. The obtained results show that the interaction between strength mismatch and crack depth affects the driving force at the SCC crack tip directly. Nevertheless, the existence of FZ and HAZ has been usually ignored when studying the mechanical properties mismatch of DMWJs in previous studies by the finite element method (FEM). It is simplified to a bimaterial or triplegate material "Sandwich" model, and the mechanical properties of the base metal and weld metal are defined, respectively. Nevertheless, the mechanical field and driving force at the tip of SCC in different positions of the welded joint are analyzed by the "Sandwich" model has been unable to meet the requirements [20-22]. To characterize the distribution of mechanical properties in the DMWJ more accurately, some scholars $[23,24]$ tried to use some subroutines in ABAQUS to realize the uneven distribution of mechanical properties varies along with the spatial position. Xue et al. [23] have established the "Sandwich" model and the heterogeneous material model of the DMWJ based on the user-defined field (USDFLD) subroutine, and the results illustrate that the heterogeneous material model compensated for the sudden change of the mechanical properties of the Sandwich model at the interface. However, only a few pieces of literature could be found on the driving force of DMWJs with heterogeneous materials.

In this study, to further study the driving force and mechanical field around the tip of SCC of DMWJs in PWRs, the stress-strain state, stress triaxiality, and J-integral at the crack tip at different positions were analyzed based on the elastic-plastic fracture mechanics approach.

\section{Geometric Model of the Welded Joint}

The geometric structure of the Alloy 52M DMWJ at the connection between the nozzle and safe-end of the PWR is shown in Figure 2(a). The operating experience of NPPs shows that the SCC behavior is more likely susceptible in weld zones $[25,26]$, which seriously threatens the safety of in-service NPPs. Several pieces of research illustrated that the interface region of the DMWJ prepared by different materials is the focus of SCC initiation $[27,28]$. In this study, the interface cracks are located on the fusion boundary line, and the length of the initial crack is $4 \mathrm{~mm}$. The location of the seven cracks is shown in Figure 2(b) and summarized in Table 1 .

\section{Calculation Model}

3.1. Material Model. The Ramberg-Osgood (R-O) equation can be adapted to express the material constitutive models of the DMWJ in PWRs [18], which is written as

$$
\frac{\varepsilon}{\varepsilon_{0}}=\frac{\sigma}{\sigma_{0}}+\alpha\left(\frac{\sigma}{\sigma_{0}}\right)^{n},
$$

where $\sigma_{0}$ is the yield strength, $\varepsilon_{0}$ is the yield strain, $\alpha$ is the coefficient of Ramberg-Osgood, and $n$ is the work hardening exponent. In order to obtain the local mechanical properties of the Alloy 52M DMWJ in detail, Wang et al. [14,15] sliced the Alloy 52M DMWJ from prefabricated material in different positions and carried out small-size plate tensile tests at $340^{\circ} \mathrm{C}$. The measured data of mechanical properties for the A508, Alloy52Mb, Alloy52Mw, and 316L are listed in Table 2. The yield strength $\sigma_{0}$ and work hardening exponent $n$ near the weld zone of the Alloy 52M DMWJ are shown in Figure 3.

Many material constitutive models have been provided to users in ABAQUS, but they are only adopted to 


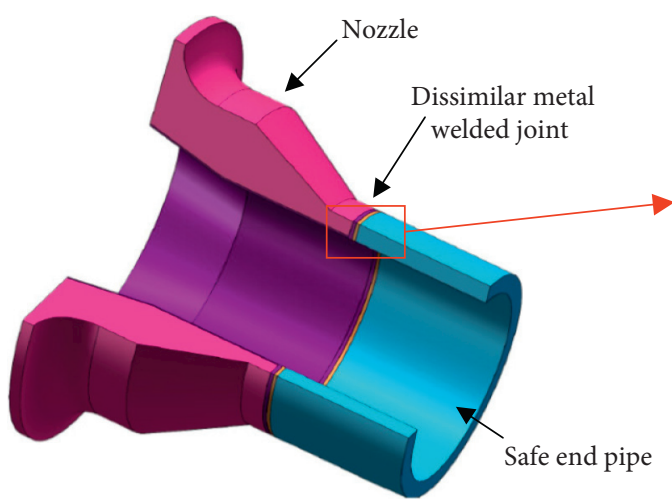

(a)

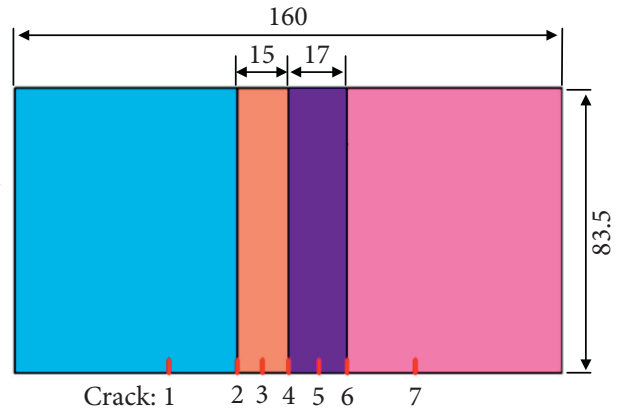

(b)

Figure 2: (a) The DMWJ structure for connecting the pipe-nozzle of a pressure vessel to the safe-end and (b) the four materials composed of the DMWJ (pipe-nozzle A508, buttering Alloy52Mb, weld Alloy52Mw, and safe-end pipe 316L).

TABLE 1: A summary of the seven cracks and their locations.

\begin{tabular}{lc}
\hline Crack number & Crack location \\
\hline Crack 1 & Center crack in the $316 \mathrm{~L}$ zone \\
Crack 2 & $316 \mathrm{~L} / \mathrm{Alloy} 52 \mathrm{Mw}$ interface \\
Crack 3 & Center crack in the Alloy $52 \mathrm{Mw}$ zone \\
Crack 4 & Alloy $52 \mathrm{Mw} /$ Alloy $52 \mathrm{Mb}$ interface \\
Crack 5 & Center cracks in the Alloy $52 \mathrm{Mb}$ zone \\
Crack 6 & Alloy $52 \mathrm{Mb} / \mathrm{SA} 508$ interface \\
Crack 7 & Center crack in the SA508 zone \\
\hline
\end{tabular}

TABLE 2: Mechanical property data of the four materials at $340^{\circ} \mathrm{C}[14,15]$.

\begin{tabular}{lccccc}
\hline Material & Young's modulus, $E(\mathrm{MPa})$ & Poisson ratio, $v$ & Yield stress, $\varepsilon_{0}(\mathrm{MPa})$ & Work hardening exponent, $n$ & Hardening parameter, $\alpha$ \\
\hline A508 & 183150 & 0.3 & 476 & 8.08 & 1.78 \\
Alloy52Mb & 180000 & 0.3 & 393 & 4.45 & 12.36 \\
Alloy52Mw & 180000 & 0.3 & 389 & 4.99 & 9.93 \\
316L & 176390 & 0.3 & 227 & 3.24 & 10.46 \\
\hline
\end{tabular}

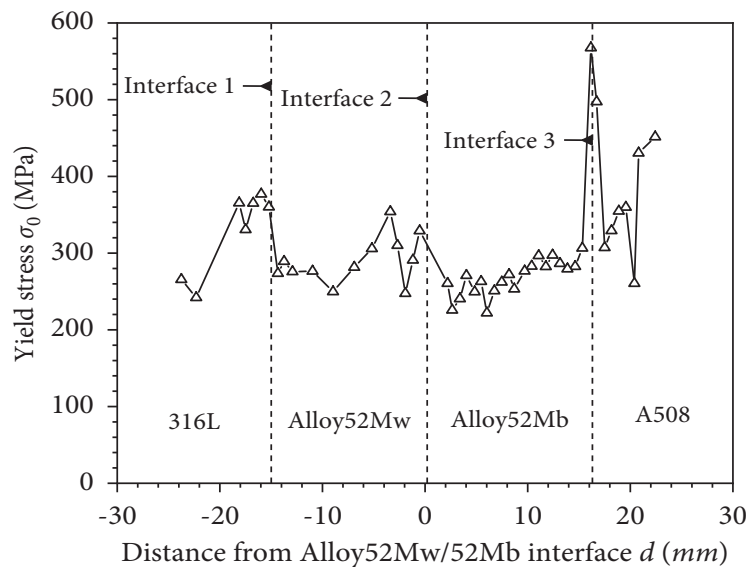

(a)

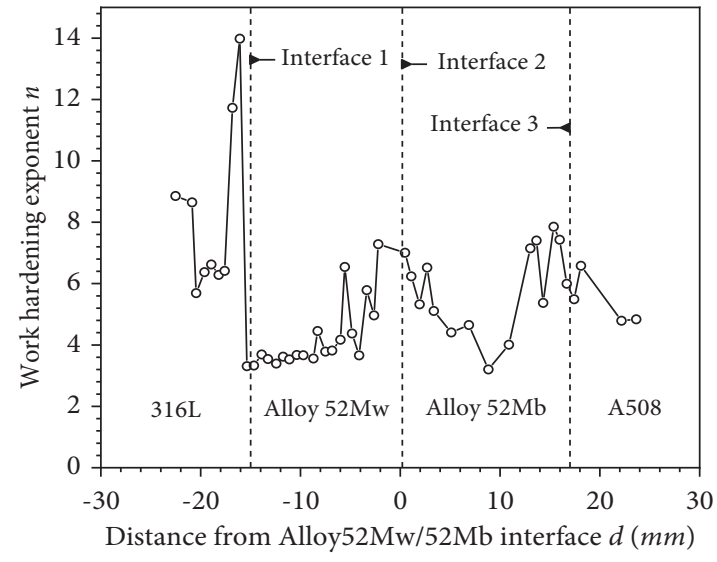

(b)

FIGURE 3: Local mechanical properties distribution of the Alloy 52M DMWJ. (a) Yield strength and (b) work hardening exponent [14, 15].

homogeneous metals. However, the material mechanical properties at DMWJs are heterogeneous, as the previous part mentioned. The USDFLD subroutine is programmed in the
FORTRAN language, which is used for redefining the mechanical properties of each integrated point in the element [29]. The flow chart was displayed in Figure 4, where 


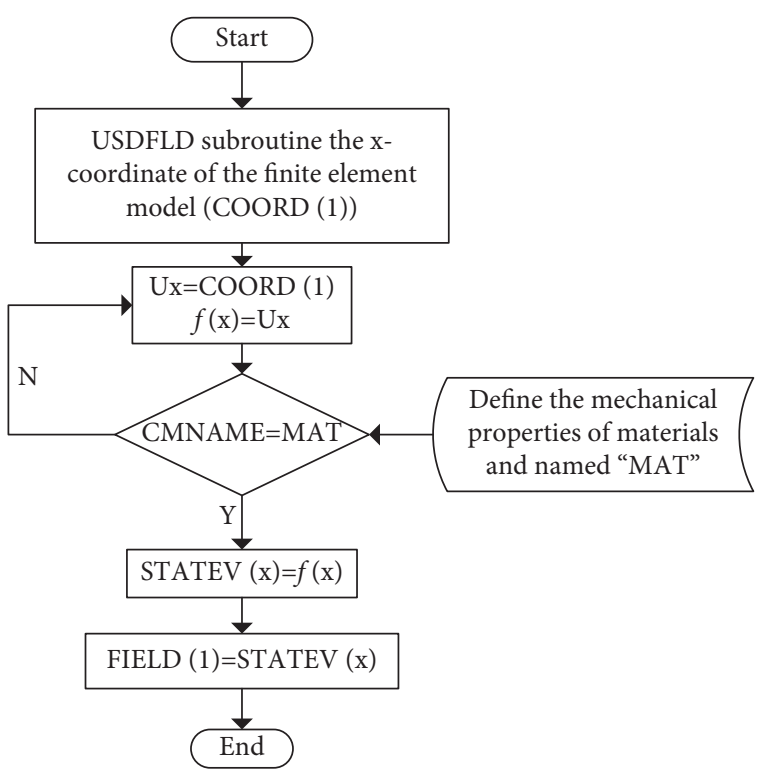

FIgURE 4: The flow chart of the USDFLD subroutine.

the functional relationship between the material mechanical properties $U \mathrm{x}$ and the field variable $f(\mathrm{x})$ was established $[23,30]$.

3.2. FEM Model. The FEM is established according to the geometric size shown in Figure 2(b). The crack front along the thickness of the Alloy 52M DMWJ specimen is mainly dominated by the plane strain condition. Therefore, the elastic-plastic finite element analysis is carried out under the condition of plane strain. The 8node biquadratic plane strain quadrilateral elements (CPE8) are adopted in the global model to obtain the accurate stress and strain distribution at the crack tip. At the same time, the calculation speed is the fastest when the global grid number is 5940 by comparison, as shown in Figure 5(a). The mesh around the crack tip is refined to eliminate the influence of the crack tip singularity on the calculation results. After checking, when the number of meshes in the $0.5 \mathrm{~mm}$ circular region of the crack tip is 1664 CPE8, the calculation effect is the best, as shown in Figure 5(b).

In order to characterize the effect of the uneven distribution of mechanical properties on the driving force of the crack tip in detail, a circular region is set at $0.2 \mathrm{~mm}$ from the crack tip as the observation path. The left region of the crack is $0 \sim 180^{\circ}$, and the right region of the crack is $0 \sim-180^{\circ}$, as shown in Figure 5(b). The stress intensity factor $\left(K_{\mathrm{I}}\right)$ is adopted as the mechanical parameter, and the constant load is taken as the loading condition. As shown in Figure 5(a), the uniform tensile load is applied on both sides of the specimen, and the parameter $K_{\mathrm{I}}=15 \mathrm{MPa} \mathrm{m}^{1 / 2}$ [29] is defined.

\section{Results and Discussions}

4.1. The Stress Condition around the Crack Tip. The stressstrain condition around the crack tip of the DMWJ in
PWRs is important for local fracture analysis and structural integrity assessments. The Mises stress $\sigma_{\mathrm{m}}$ contour around the crack tip is shown in Figure 6, where Figures 6(a), 6(c), $6(\mathrm{e})$, and $6(\mathrm{~g})$ are the Mises stress contours around the tip of the SCC of the noninterface. It can be seen that the contour around the crack tip of the noninterface presents a slight asymmetric distribution along both sides of the crack due to heterogeneous material properties of the Alloy $52 \mathrm{M}$ DMWJ. The field area of the Mises stress around the crack tip in the weld metal is significantly smaller than that of the base metal under the same external load conditions. Figures 6(b), 6(d), and 6(f) are the Mises stress contours around the crack tip of the interface, where the contour around the crack tip is asymmetrically distributed along both sides of the crack due to the dramatic change of the material properties at the interface, and the most obvious is the Mises stress contour distribution at the interface between A508 and Alloy $52 \mathrm{Mb}$. The discussion above illustrate that the material constraint effect of the Alloy $52 \mathrm{M}$ DMWJ caused by the welding progress will cause the asymmetric distribution of the Mises stress contour around the crack tip. In addition, the asymmetric Mises stress contour of the interface crack tip is more evident than the noninterface crack tip.

Figure 7 represents the stress curves along the observation path of the tip of the SCC in the 316L, Alloy52Mw, Alloy52Mb, and SA508. Figures 7(a) and 7(b) show the Mises stress $\sigma_{\mathrm{m}}$ and tensile stress $\sigma_{11}$ at the crack tip, respectively. It can be seen from Figure 7 that the distribution trend of the Mises stress is consistent with that of the tensile stress at the crack tip, and the four curves are almost symmetrically distributed along the crack tip at $\Phi=0^{\circ}$. There are two maximum points in each curve, and the absolute value of the angle corresponding to each of the maxima is the same. It indicates that the heterogeneous mechanical properties distribution of the Alloy 52M DMWJ does not cause the uneven distribution of the stress state at the crack tip of the noninterface crack. The crack tip stress value of crack 1 in the SA508 zone is larger than that of the other three cracks, which shows that larger tensile stress will be obtained at the crack tip of the SA508 zone when the tensile load is kept constant. Meanwhile, it will promote the growth of the I-type crack.

The stress curves along the observation path of cracks 2, 4, and 6 are shown in Figure 8, where Figures 8(a) and 8(b) are Mises stress $\sigma_{\mathrm{m}}$ curves and tensile stress $\sigma_{11}$ curves of the crack tip, respectively. It is obvious from Figure 8 that the stress curve of crack 6 is asymmetrically distributed along the crack tip at $\Phi=0^{\circ}$, and the maximum stress at the crack tip deviates to the SA508 zone. It demonstrates that the yield strength of the SA508 zone is greater than that of the Alloy $52 \mathrm{Mb}$ zone, which is per Figure 4(a). The stress curves of cracks 2 and 4 are not completely symmetrical along the crack tip at $\Phi=0^{\circ}$ either. As shown in Figure 8, the tensile stress at the crack tip of crack 2 is greater than that of the other curves. It is indicated that larger tensile stress will be provided for the I-type crack when it is located at the interface between the $316 \mathrm{~L}$ region and base metal. 


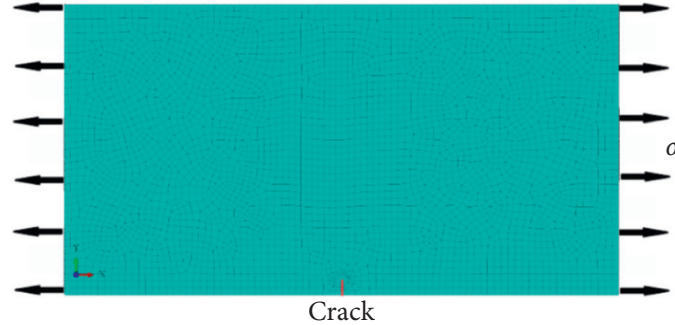

(a)

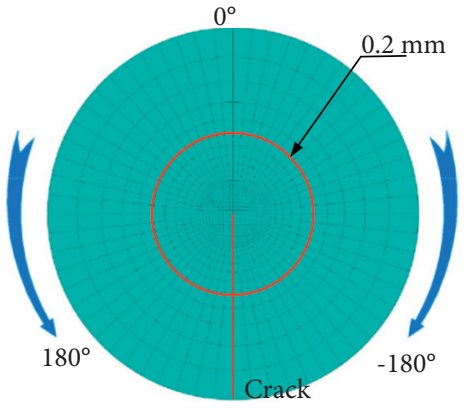

(b)

Figure 5: Mesh division of the finite element model. (a) Global model and (b) crack tip refinement mesh.

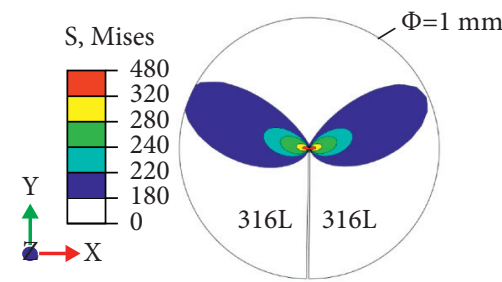

(a)

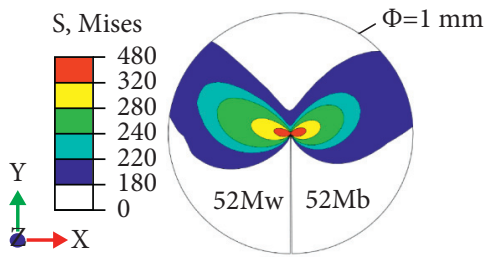

(d)

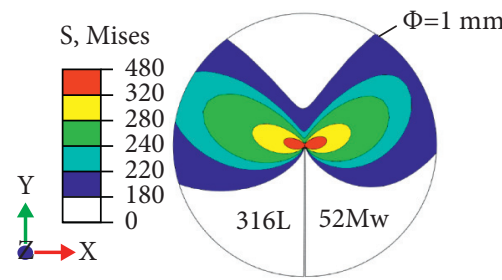

(b)
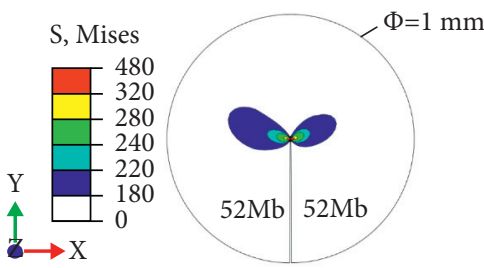

(e)

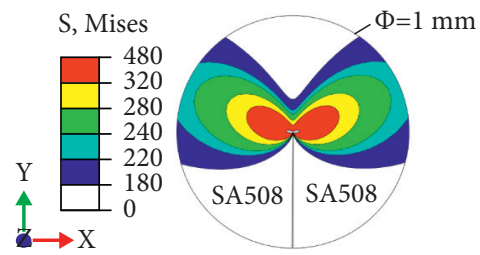

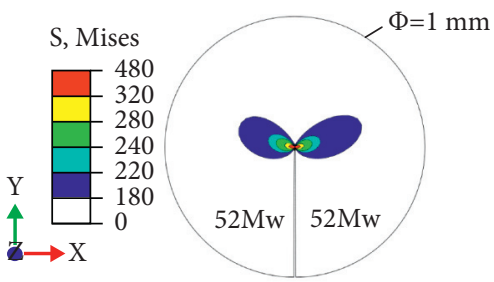

(c)

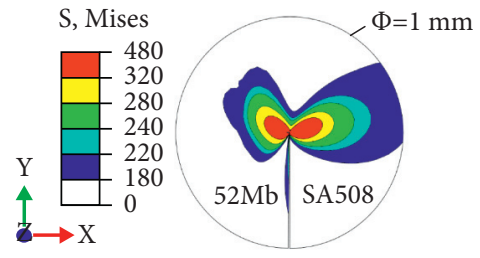

(f)

(g)

Figure 6: The Mises stress (S, Mises) contour around the crack tip. (a) Crack 1. (b) Crack 2. (c) Crack 3. (d) Crack 4. (e) Crack 5. (f) Crack 6. (g) Crack 7.

4.2. The Strain Condition around the Crack Tip. The equivalent plastic strain $\varepsilon_{\text {eq }}$ contours around the crack tip is shown in Figure 9, where Figures 9(a), 9(c), 9(e), and 9(g) are the equivalent plastic strain contour around the crack tip of the noninterface. Similar to the Mises stress contours around the crack tip, the equivalent plastic strain contour around the crack tip presents a slight asymmetric distribution along both sides of the crack. Combined with the material properties displayed in Figure 3, it indicates that the field area of the equivalent plastic strain contour around the crack tip of the high-strength base metal (SA508) is smaller than that of the welded metal. Figures 9(b), 9(d), and 9(f) are the equivalent plastic strain contour around the crack tip in the interface. It can be seen that the contour around the crack tip of the interface is asymmetric, which indicates that the plastic deformation on both sides of the interface crack is asymmetric under the same load conditions. Compared with other scholars' research, the continuous asymmetric stressstrain contours around the crack tip in the interface region were based on the heterogeneous material model, while the traditional "Sandwich" material model will produce mutation contours at the interface $[23,31]$. Therefore, the heterogeneous mechanical properties will cause the complex distribution of the crack tip stress-strain field, regardless of the "Sandwich" or the heterogeneous material model.

Figure 10 shows the strain curve along the observation path of the crack tip for $316 \mathrm{~L}$, Alloy52Mw, Alloy52Mb, and SA508. Figures $10(\mathrm{a})$ and 10 (b) are the equivalent plastic 


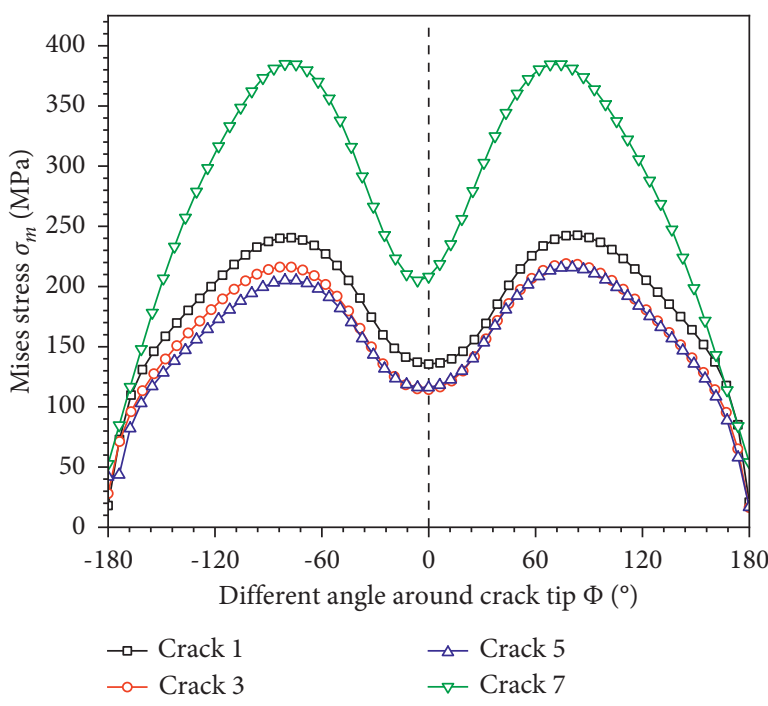

(a)

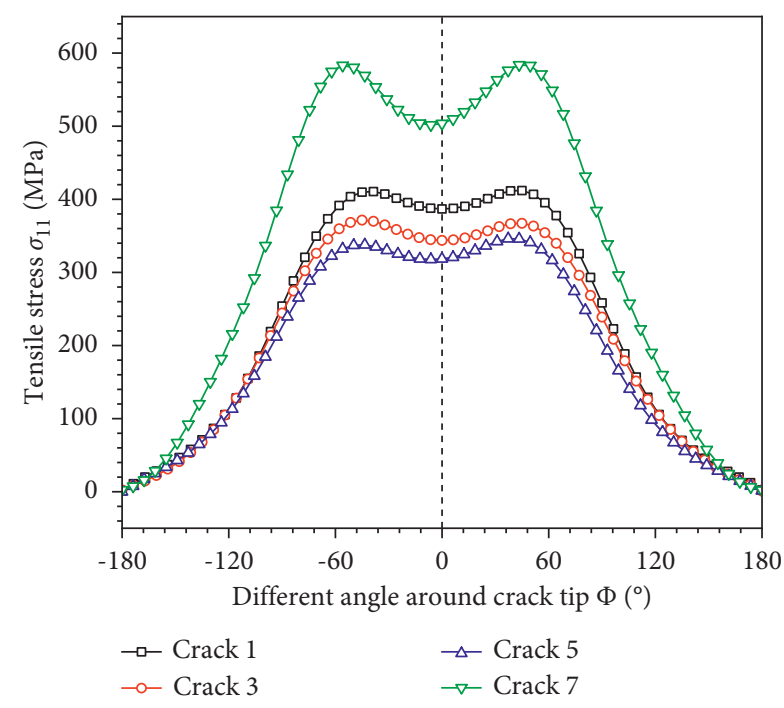

(b)

FIgURE 7: The stress curve at the crack tip of the noninterface. (a) Mises stress and (b) tensile stress.



(a)

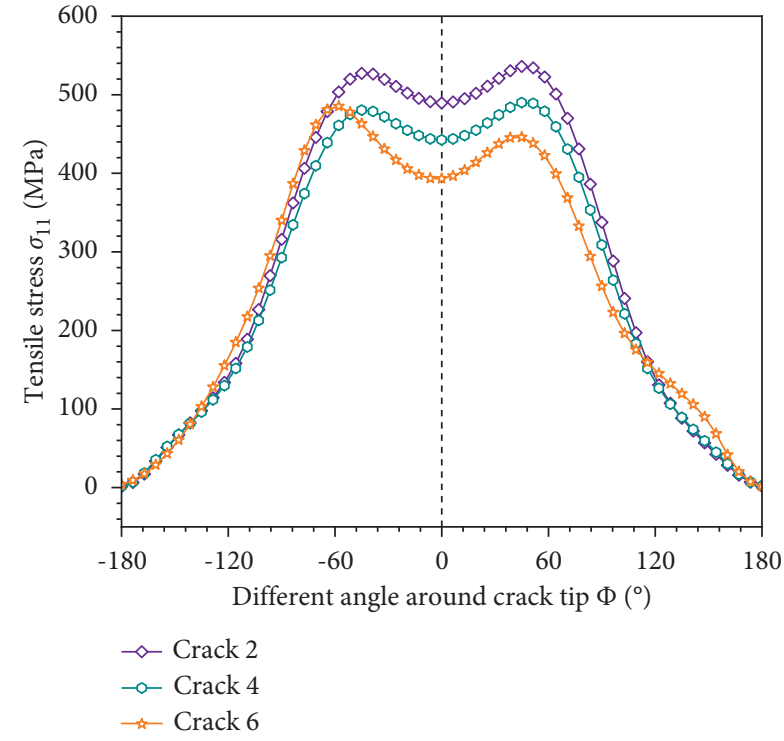

(b)

Figure 8: The stress curve at the crack tip of the interface. (a) Mises stress and (b) tensile stress.

strain $\varepsilon_{\text {eq }}$ and tensile strain $\varepsilon_{11}$ curve of the crack tip, respectively. It is evident from Figure 10 that the strain curve of cracks 1 and 7 has symmetrical distribution along the crack tip at $\Phi=0^{\circ}$ but that of cracks 3 and 5 does not. The plastic strain on the left $0 \sim-180^{\circ}$ of crack 3 is less than that on the right $0 \sim 180^{\circ}$. Conversely, the plastic strain on the left $0 \sim-180^{\circ}$ of crack 5 is larger than that on the right $0 \sim 180^{\circ}$. It demonstrates that the plastic strain near the crack tip of the base metal side is relatively smaller when the crack is in the weld metal. Furthermore, there is less plastic constraint loss near the crack tip of the base metal side. At the same time, the heterogeneous mechanical properties of the Alloy 52M
DMWJ cause the uneven distribution of the plastic strain at the crack tip in the base metal, which has a negligible effect on the base metal. By comparing the numerical values of the curves in Figure 10, it can be concluded that the plastic strain at the crack tip in the 316L region is the largest under the same external load condition and the plastic strain at the crack tip is the smallest in the SA508 region.

The strain curves along the observation path of cracks 2 , 4, and 6 are shown in Figure 11. Figures 11(a) and 11(b) are the equivalent plastic strain $\varepsilon_{\text {eq }}$ curve and normal plastic strain $\varepsilon_{11}$ curve of the crack tip, respectively. The distribution trend of the equivalent plastic strain $\varepsilon_{\mathrm{eq}}$ is consistent with 


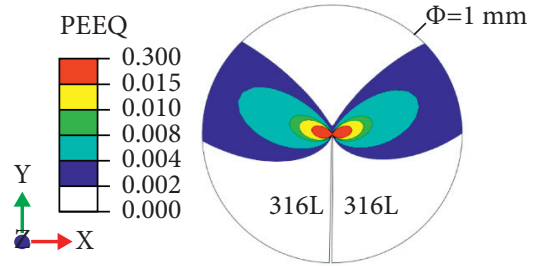

(a)

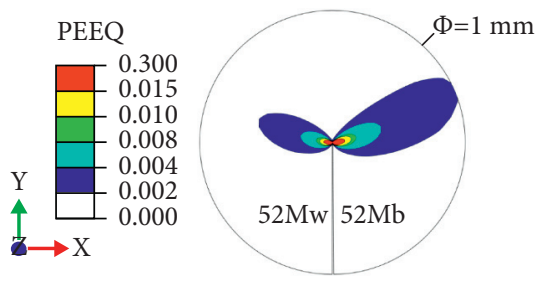

(d)
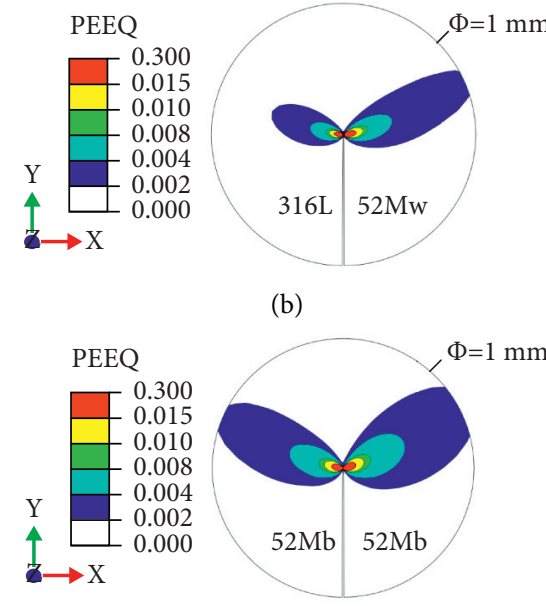

(e)

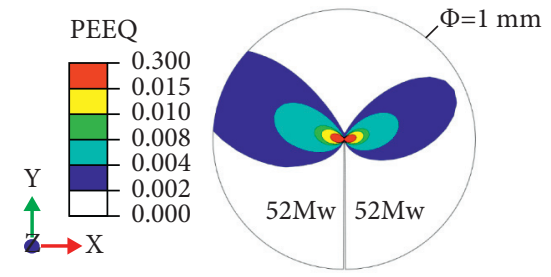

(c)
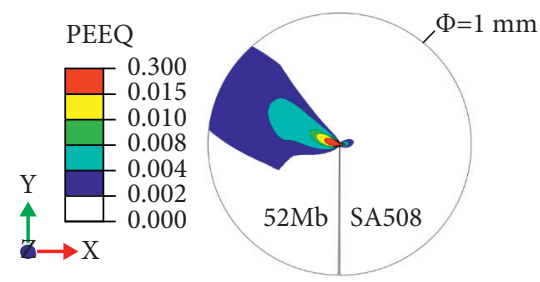

(f)

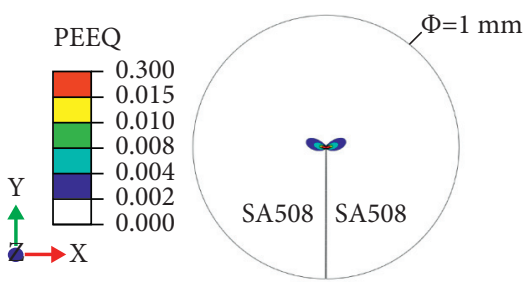

(g)

Figure 9: The equivalent plastic strain $\varepsilon_{\text {eq }}$ contour around the crack tip. (a) Crack 1. (b) Crack 2. (c) Crack 3. (d) Crack 4 . (e) Crack 5. (f) Crack 6. (g) Crack 7.

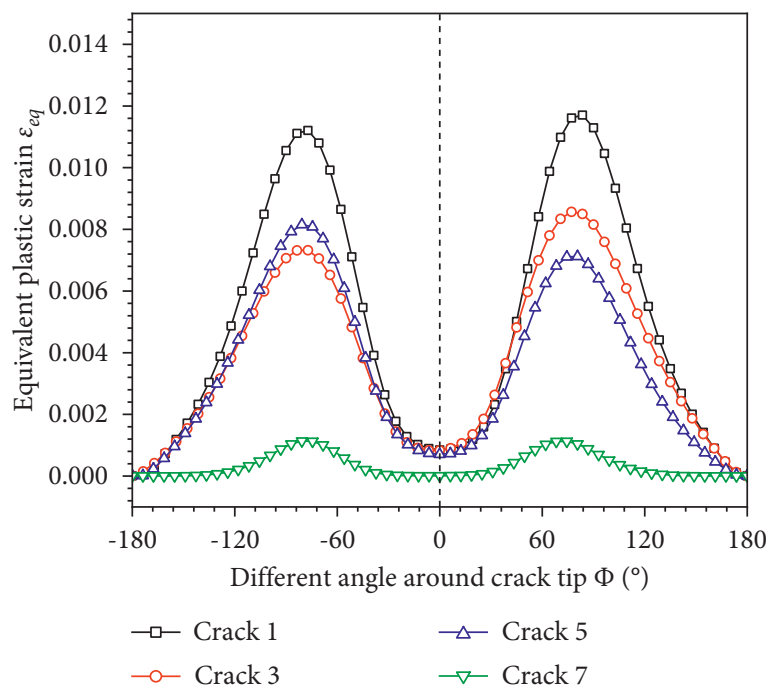

(a)

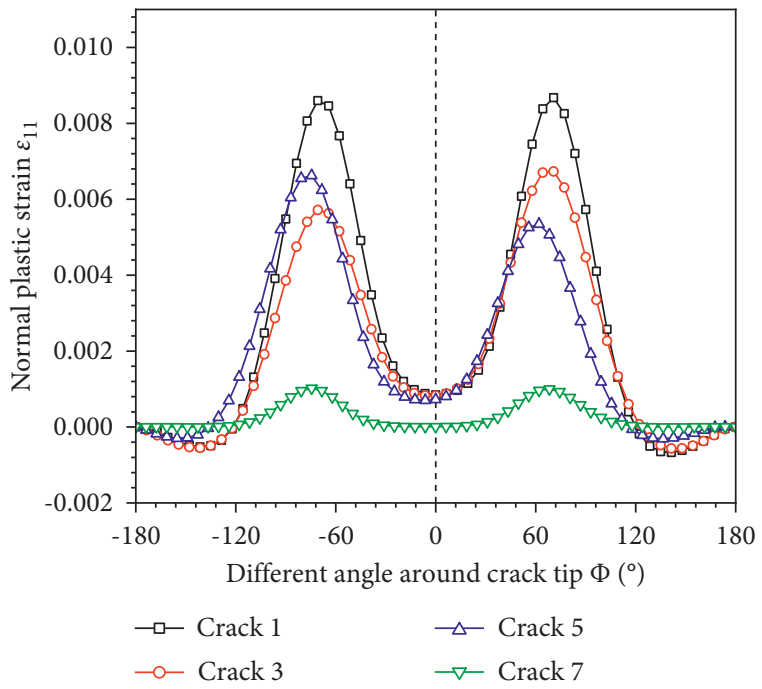

(b)

FIgURE 10: The strain curve at the crack tip of the noninterface. (a) Equivalent plastic strain and (b) normal plastic strain.

that of the tensile strain $\varepsilon_{11}$ at the crack tip, and the curve is not symmetrically distributed along the crack tip $\Phi=0^{\circ}$. The strain curves of cracks 2 and 4 are very close to each other. From the strain distribution curve of cracks 2 and 6, it is evident that the plastic strain at the crack tip of the base metal is smaller than that at the weld metal.
4.3. The Stress Triaxiality around the Crack Tip. The stress triaxiality and equivalent plastic strain combination are considered the main driving force for the SCC initiation $[14,15]$. The stress triaxiality at the crack tip is defined as the ratio of the hydrostatic stress $\sigma_{\mathrm{eq}}$ to Mises stress $\sigma_{\mathrm{m}}$. Figure 12(a) shows the stress triaxiality curves of the 


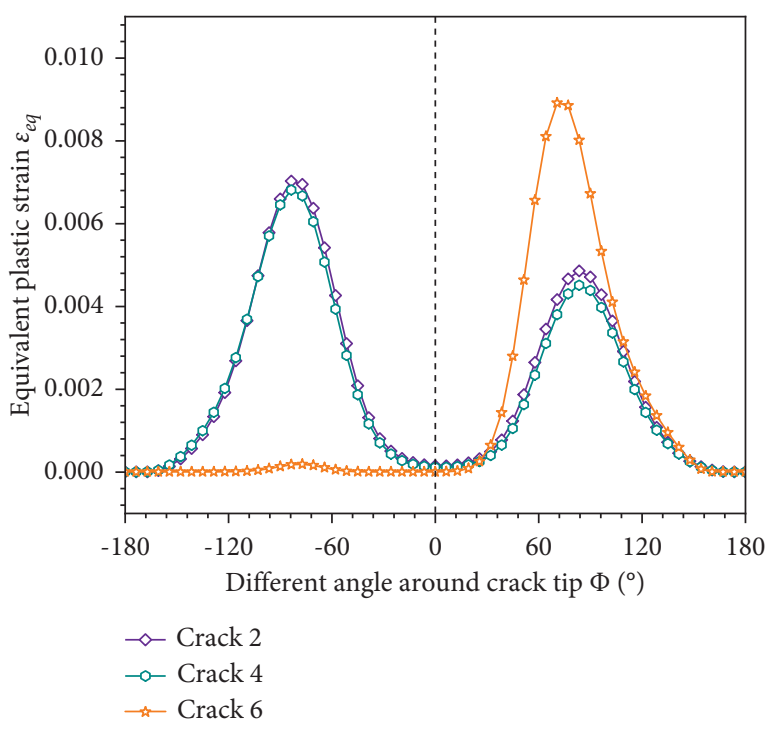

(a)

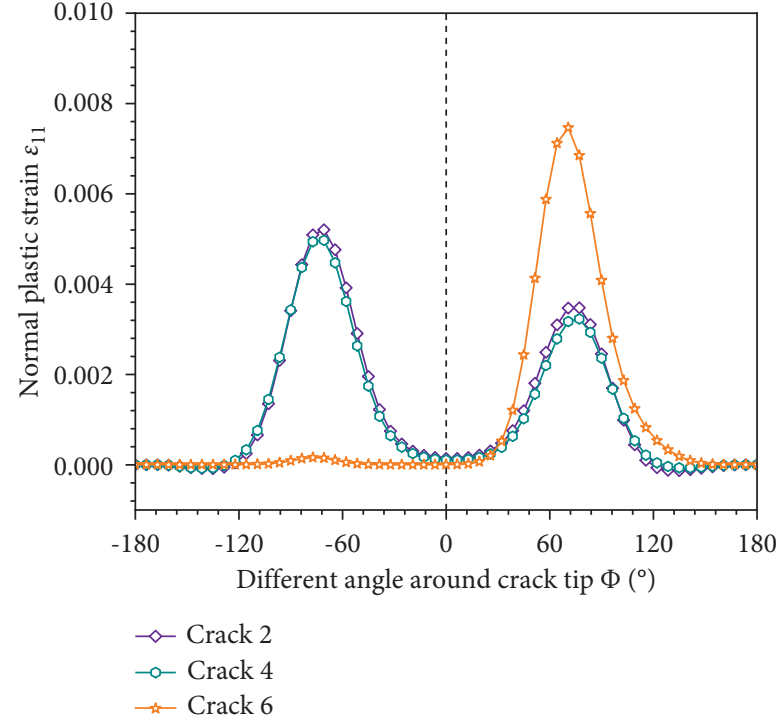

(b)

Figure 11: The strain curve at the crack tip of the interface. (a) Equivalent plastic strain and (b) normal plastic strain.

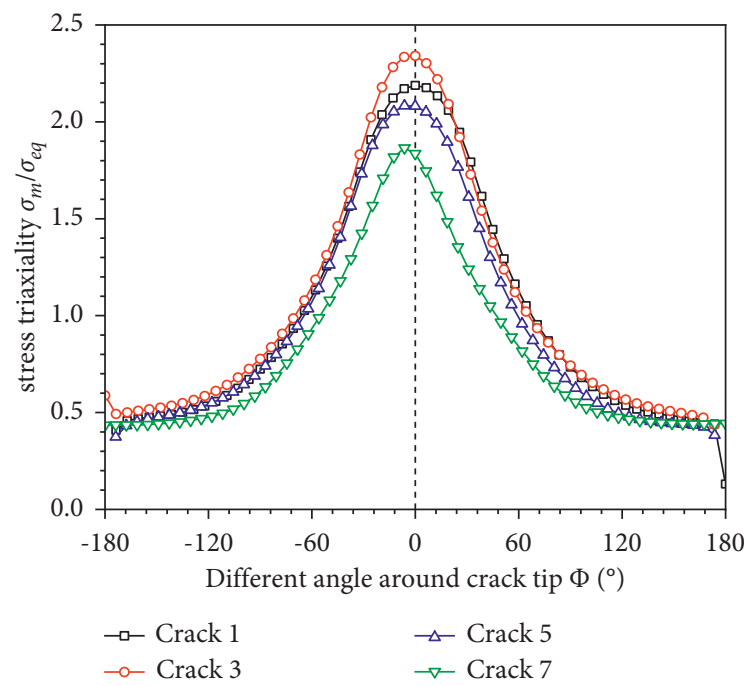

(a)

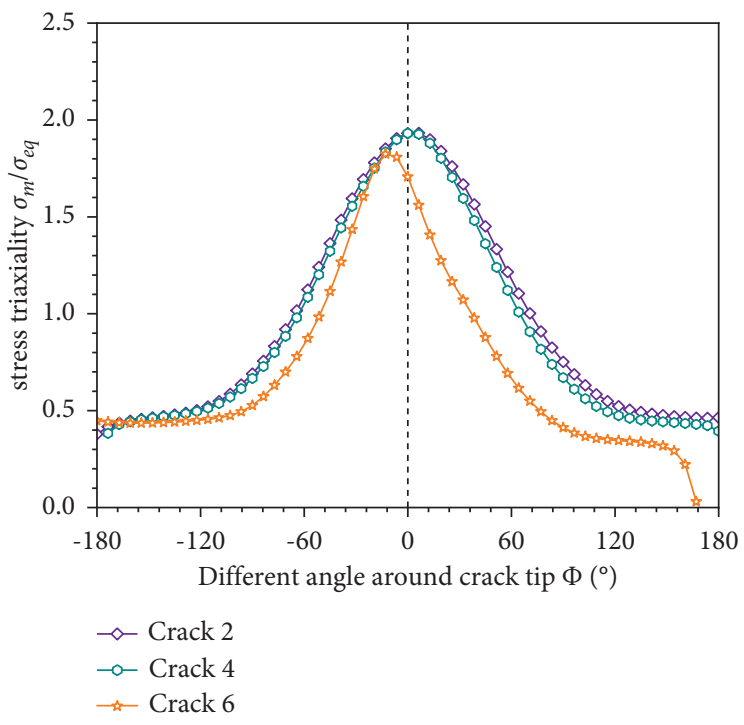

(b)

FIGURE 12: The stress triaxiality curve at the crack tip.

crack tip along the observation path in $316 \mathrm{~L}$, alloy52Mw, alloy $52 \mathrm{Mb}$, and SA508, where the stress triaxiality of the crack tip distributes symmetrically along the crack tip at $\Phi=0^{\circ}$. The stress triaxiality of the crack tip is the largest in the Alloy52Mw zone and the smallest in the SA508 region. The plastic strain and stress triaxiality at the crack tip in the 316L region are larger than those at the crack tip in other regions. Therefore, a larger driving force is required for the SCC initiation when the crack is in the $316 \mathrm{~L}$ zone. It can be seen that the SA508 region is safer than those in other zones. The stress triaxiality curve of the interface crack tip along the observation path is shown in
Figure 12(b). The stress triaxiality curves of cracks 2 and 4 are very close to each other. The stress triaxiality curve at the crack tip of crack 6 is not symmetrically distributed along the crack tip at $\Phi=0^{\circ}$, and the maximum value of the stress triaxiality curve is biased towards the Alloy $52 \mathrm{Mw}$ zone. Therefore, crack 6 is more likely to extend to the Alloy52Mw region.

4.4. J-Integral in the Welded Joint Specimen. J-integral is a fracture parameter to characterize the driving force of the crack tip. The black curve in Figure 13 shows the 


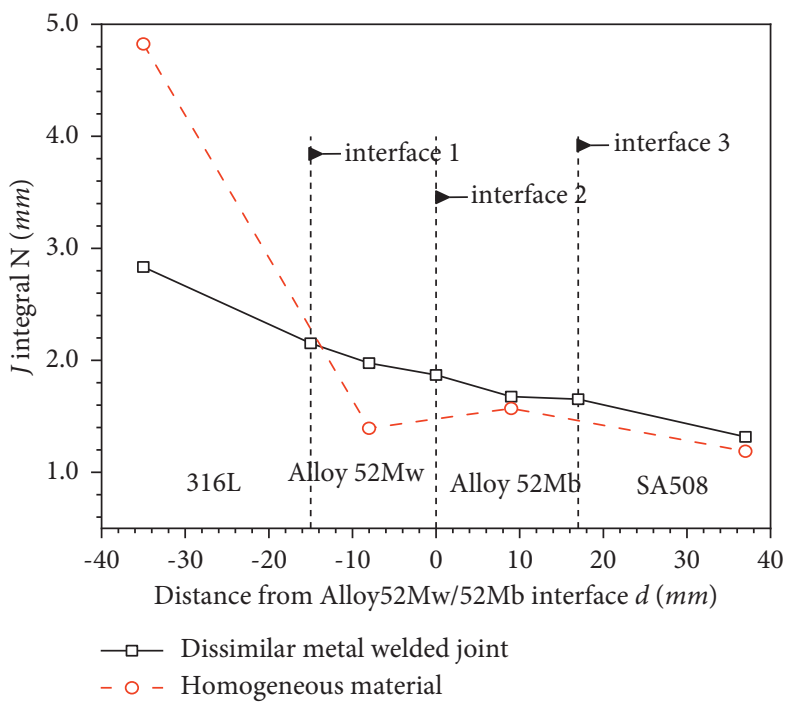

FIGURE 13: J-integral of the crack tip of the welded joint.

$J$-integral numerical distribution of the crack tip at different positions of the Alloy 52M DMWJ, and the imaginary red curve shows the $J$-integral numerical distribution of the homogeneous material model under the same load conditions. It indicates that the $J$-integral at the crack tip is the largest in the $316 \mathrm{~L}$ zone, whether in the heterogeneous metal-welded joint model or the homogeneous material model. On the other hand, the crack located in the SA508 region is the smallest. For the Alloy $52 \mathrm{M}$ DMWJ, the $J$-integral numerical value is decreased from the 316L zone to the SA508 region under the same load conditions. Compared with the J-integral numerical value of the crack tip of the homogeneous material, the heterogeneous mechanical properties of the Alloy 52M DMWJ have inhibition on the J-integral of the crack tip in the $316 \mathrm{~L}$ zone. Conversely, it can promote the J-integral of the crack in the SA508 region and weld metal, and the promoting effect on the $J$-integral of welding material Alloy52 Mw is quite evident. The J-integral at the SCC crack tip of the Alloy 52M DMWJ based on the heterogeneous materials model has the same trend as that obtained by Zhao et al. [32] using the "Sandwich" material model.

\section{Conclusions}

In this research, the stress-strain condition, stress triaxiality, and $J$-integral of the SCC tip at different positions of the Alloy 52M DMWJ are analyzed based on the heterogeneous material model. The main acquired results are summarized as follows:

(1) When the stress intensity factor $K_{\mathrm{I}}$ is constant, the heterogeneous mechanical properties of the Alloy $52 \mathrm{M}$ DMWJ do not cause the uneven distribution of the stress state at the crack tip of the noninterface crack. But the stress curve of the interface crack is showing asymmetrical distribution along the crack tip.
(2) By combining the stress-strain condition of the Alloy $52 \mathrm{M}$ DMWJ at different SCC tips positions, the larger tensile stress would be provided for the I-type crack when the crack is in the SA508 zone and the interface between the 316L region and base metal.

(3) When the stress intensity factor $K_{\mathrm{I}}$ is constant, the $J$ integral at the tip of SCC in the Alloy 52M DMWJ decreases from the 316L region to the SA508 zone. The heterogeneous mechanical properties have inhibition on the J-integral of the crack in the $316 \mathrm{~L}$ region. On the other hand, it has a promoting effect when the crack is in the SA508 zone and weld metal.

\section{Data Availability}

The numerical simulation data of stress-strain condition, the stress triaxiality, and J-integral of the dissimilar metal welded joint used to support the findings of this study are included within the article.

\section{Conflicts of Interest}

The authors declare no conflicts of interest.

\section{Acknowledgments}

This work was supported by the National Natural Science Foundation of China (52075434) and Natural Science Foundation of Shaanxi Provincial Department of Education (2021KW-36, 2021JM-389).

\section{References}

[1] K. J. Stephenson and G. S. Was, "Crack initiation behavior of neutron irradiated model and commercial stainless steels in high temperature water," Journal of Nuclear Materials, vol. 444, no. 1-3, pp. 331-341, 2014.

[2] F. P. Ford, "Mechanisms of environmentally-assisted cracking. (Low alloy steels in light water reactor environments)," International Journal of Pressure Vessels and Piping, vol. 40, no. 5, 1989. 
[3] X. Lou, P. L. Andresen, and R. B. Rebak, "Oxide inclusions in laser additive manufactured stainless steel and their effects on impact toughness and stress corrosion cracking behavior," Journal of Nuclear Materials, vol. 499, pp. 182-190, 2018.

[4] R. Chaudhari, P. K. Loharkar, and A. Ingle, "Applications and challenges of arc welding methods in dissimilar metal joining," IOP Conference Series: Materials Science and Engineering, vol. 810 , no. 1, p. 012006, 2020.

[5] P. L. Andresen, "A brief history of environmental cracking in hot water," Corrosion, vol. 75, no. 3, pp. 240-253, 2019.

[6] H. P. Seifert, S. Ritter, T. Shoji, Q. J. Peng, Y. Takeda, and Z. P. Lu, "Environmentally-assisted cracking behaviour in the transition region of an Alloy182/SA $508 \mathrm{Cl} .2$ dissimilar metal weld joint in simulated boiling water reactor normal water chemistry environment," Journal of Nuclear Materials, vol. 378, no. 2, pp. 197-210, 2008.

[7] A. R. Jenks, G. A. White, and P. Crooker, "Scoring process for evaluating laboratory PWSCC crack growth rate data of thickwall alloy 690 wrought material and alloy 52, 152, and variant weld material," The Minerals, Metals \& Materials Series, pp. 3-14, 2019.

[8] P. L. Andresen and M. M. Morra, "IGSCC of non-sensitized stainless steels in high temperature water," Journal of Nuclear Materials, vol. 383, no. 1-2, pp. 97-111, 2008.

[9] H. Ming, Z. Zhang, J. Wang, E.-H. Han, and W. Ke, "Microstructural characterization of an SA508-309L/308L-316L domestic dissimilar metal welded safe-end joint," Materials Characterization, vol. 97, pp. 101-115, 2014.

[10] H. Ming, R. Zhu, Z. Zhang et al., "Microstructure, local mechanical properties and stress corrosion cracking susceptibility of an SA508-52M-316LN safe-end dissimilar metal weld joint by GTAW," Materials Science and Engineering A, vol. 669, pp. 279-290, 2016.

[11] Z. Lingyan, C. Yinghao, and X. He, "Effect of mechanical heterogeneity on the crack driving force of a reactor pressure vessel outlet nozzle DMW joint," IOP Conference Series: Materials Science and Engineering, vol. 280, p. 012031, 2017.

[12] X. Di, D. Geng, S. Wu, D. Wang, Z. Zhang, and C. Li, "Solidification behaviour and microstructure of welding transition zone using low-transformation-temperature welding consumables," Science and Technology of Welding \& Joining, vol. 24, no. 2, pp. 148-155, 2019.

[13] C. Yuce, M. Tutar, F. Karpat, and N. Yavuz, "The optimization of process parameters and microstructural characterization of fiber laser welded dissimilar HSLA and MART steel joints," Metals, vol. 6, no. 10, p. 245, 2016.

[14] H. T. Wang, G. Z. Wang, F. Z. Xuan, C. J. Liu, and S. T. Tu, "Local mechanical properties and microstructures of Alloy52M dissimilar metal welded joint between A508 ferritic steel and 316L stainless steel," Advanced Materials Research, vol. 509, pp. 103-110, 2012.

[15] H. T. Wang, G. Z. Wang, F. Z. Xuan, C. J. Liu, and S. T. Tu, "Local mechanical properties of a dissimilar metal welded joint in nuclear powersystems," Materials Science and Engineering $A$, vol. 568, pp. 108-117, 2013.

[16] H. Cetinel, B. Uyulgan, and T. Aksoy, "The effect of yield strength mismatch on the fracture behavior of welded nodular cast iron," Materials Science and Engineering A, vol. 387-389, pp. 357-360, 2004.

[17] Y. J. Kim and K. H. Schwalbe, "Numerical analyses of strength mis-match effect on local stresses for ideally plastic materials," Engineering Fracture Mechanics, vol. 71, no. 7-8, pp. 11771199, 2004.
[18] L. Dong, Q. Peng, H. Xue, E.-H. Han, W. Ke, and L. Wang, "Correlation of microstructure and stress corrosion cracking initiation behaviour of the fusion boundary region in a SA508 Cl. 3-Alloy 52M dissimilar weld joint in primary pressurized water reactor environment," Corrosion Science, vol. 132, pp. 9-20, 2018.

[19] J. Hou, Q. J. Peng, Y. Takeda et al., "Microstructure and mechanical property of the fusion boundary region in an Alloy 182-low alloy steel dissimilar weld joint," Journal of Materials Science, vol. 45, no. 19, pp. 5332-5338, 2010.

[20] Z. R. Chen, Y. H. Lu, X. F. Ding, and T. Shoji, "Microstructural and hardness investigations on a dissimilar metal weld between low alloy steel and Alloy 82 weld metal," Materials Characterization, vol. 121, pp. 166-174, 2016.

[21] H. Ming, Z. Zhang, J. Wang, E.-H. Han, P. Wang, and Z. Sun, "Microstructure of a safe-end dissimilar metal weld joint (SA508-52-316L) prepared by narrow-gap GTAW," Materials Characterization, vol. 123, pp. 233-243, 2017.

[22] T. Sarikka, M. Ahonen, R. Mouginot et al., "Microstructural, mechanical, and fracture mechanical characterization of SA 508-Alloy 182 dissimilar metal weld in view of mismatch state," International Journal of Pressure Vessels and Piping, vol. 145, pp. 13-22, 2016.

[23] H. Xue, Y. Sun, S. Zhang et al., "A numerical approach to analyze detail mechanical characteristic at the crack tip of SCC in dissimilar metal welded joints," Advances in Materials Science and Engineering, vol. 2021, Article ID 8429051, 12 pages, 2021.

[24] H. Xue, Y. Bi, S. Wang, J. Zhang, and S. Gou, "Compilation and application of UMAT for mechanical properties of heterogeneous metal welded joints in nuclear power materials," Advances in Materials Science and Engineering, vol. 2019, Article ID 3151823, 12 pages, 2019.

[25] W. Bamford, B. Newton, and D. Seeger, "Recent experience with weld overlay repair of indications in alloy 182 butt welds in two operating PWRs," ASME Pressure Vessels and Piping Conference, vol. 47578, pp. 427-434, 2006.

[26] L. G. L. G. F. Kewei, P. J. Y. W. Z. Maolong, and S. U. N. Zhiyuan, "Stress corrosion cracking behavior of dissimilar metal weld A508/52M/316L in high temperature water environment," Acta Metallurgica Sinica, vol. 47, no. 7, pp. 797-803, 2011.

[27] N. Gubeljak, O. Kolednik, J. Predan, and M. Oblak, "Effect of strength of mismatch interface on crack driving force," Key Engineering Materials, vol. 251-252, pp. 235-244, 2003.

[28] Y. Wang, H. Cui, M. Fan, Y. Chen, and F. Lu, "Characterization on the gradient microstructure near the fusion interface of dissimilar metal between high Cr heat-resistant steel and Ni-based Alloy 617," Materials Characterization, vol. 151, pp. 227-236, 2019.

[29] Abaqus, Version 6.14 Documentation, Dassault Systèmes Simulia Corp., Providence, RI, USA, 2014.

[30] S. Zhou, Z. Wang, J. Zhou, and X. Wu, "Experimental and numerical investigation on bolted composite joint made by vacuum assisted resin injection," Composites Part B: Engineering, vol. 45, no. 1, pp. 1620-1628, 2013.

[31] H. Xue, K. Ogawa, and T. Shoji, "Effect of welded mechanical heterogeneity on local stress and strain ahead of stationary and growing crack tips," Nuclear Engineering and Design, vol. 239, no. 4, pp. 628-640, 2009.

[32] L. Y. Zhao, H. Xue, F. Q. Yang, and Y. K. Gui, "Analysis on mechanical parameters at SCC tip in fusion boundary region of dissimilar weld joint," Applied Mechanics and Materials, vol. 457, pp. 459-462, 2014. 